\title{
Underserved, Other Than Rural Health
}

National Cancer Institute

\section{Source}

National Cancer Institute. Underserved, Other Than Rural Health. NCI Thesaurus. Code C19101.

This includes elderly, low-literacy, blue collar, and poor populations. Minorities per se are not included but often belong to one or more or the included categories. Does not include rural. 